\title{
INVASIVE ASPERGILLOSIS ASSOCIATED WITH SYSTEMIC LUPUS ERYTHEMATOSUS AND CARDIAC POSTOPERATIVE COMPLICATION
}

\author{
Danielle Patrícia Cerqueira Macêdo ${ }^{1 *}$; Heraldo Maia Silva-Júnior²; Cristina Maria de Souza-Motta ${ }^{1}$; \\ Eveline Pípolo Milan ${ }^{3}$; Rejane Pereira Neves ${ }^{1}$
}

\author{
${ }^{1}$ Departamento de Micologia, Centro de Ciências Biológicas, Universidade Federal de Pernambuco, Recife, PE, Brasil; \\ ${ }^{2}$ Hospital Geral Otávio de Freitas, Recife, PE, Brasil; ${ }^{3}$ Departamento de Infectologia, Universidade Federal do Rio Grande \\ do Norte, Natal, RN, Brasil.
}

Submitted: March 17, 2008; Returned to authors for corrections: January 09, 2009; Approved: February 15, 2009.

\begin{abstract}
Aspergillus is a ubiquitous fungus which can cause a variety of clinical syndromes. This fungus has emerged as agent of systemic infections and has therefore gained considerable public health importance. This paper describes two cases of invasive aspergillosis caused by A. fumigatus in immuno-suppressed patients and underscores the importance of early identification of Aspergillus infection associated with systemic lupus erythematosus and cardiac postoperative complications.
\end{abstract}

Key words: Aspergillus fumigatus, opportunistic mycosis, systemic lupus erythematosus, cardiac postoperative complications.

The incidence of invasive aspergillosis has increased during the last decade due to the widespread use of powerful immunosuppressive drugs used for the treatment of diseases such as systemic lupus erythematosus and endocarditis. Invasive aspergillosis is becoming a frequent clinical picture related to the degree of immunosuppression which has a significant influence on the evolution, dissemination and morbidity of the infection $(2,16)$. For this reason an early diagnosis and treatment are essential for survival $(15,32)$. Here we report two cases of Aspergillus fumigatus infection in patients with a standard pattern of immunosuppression and focus on some of the factors that were important in influencing clinical outcome.

\section{Case 1}

A 34-year-old woman was diagnosed with systemic lupus erythematosus and treated with glucocorticoids over a period of two years. Following improvement in clinical and laboratorial tests, she was discharged. Four months later, the patient presented intense abdominal pain, high fever and renal failure. She was submitted to continuous peritoneal dialysis and developed a suggestive fungal peritonitis.
Direct examination of fresh abdominal fluid (peritoneal effluent) revealed broad septate dichotomously branched hyphae. Cultures on routine media such as Sabouraud dextrose agar with $50 \mathrm{mg}$ chloranphenicol/L were incubated at room temperature and at $37^{\circ} \mathrm{C}$, exhibiting after $48 \mathrm{~h}$ growth suggestive of Aspergillus. Macroscopically the culture produced a flat, white colony that quickly became gray-green with the conidia production. The texture varied from strictly velvety to deep felt, floccose. The reverse was colorless. Conidia mass of the conidial heads were columnar and compact. They ranged in size from 200 to $400 \mu$ by $50 \mu$. Microscopically, conidiophores were short, smooth, and up to $300 \mu$ in length and 5 to $8 \mu$ in diameter (Fig. 1). Identification of A. fumigatus was performed according to the criteria developed by Hoog et al. (14) and Rapper and Fennel (23).

As soon as the diagnosis of fungal peritonitis was confirmed, amphotericin B $(1 \mathrm{mg} / \mathrm{kg} /$ day $)$ was given intravenously in increasing doses up to a total dose of $1.13 \mathrm{~g}$. The peritoneal catheter was removed and the patient was successfully treated.

Aspergillus peritonitis had occurred as a complication of chronic ambulatory peritoneal dialysis $(17,20,28)$ and the removal

*Corresponding Author. Mailing address: Rua Cardeal Arcoverde, 116, apto 203, Graças, Recife, PE, Brasil. Tel.: 52011-240. Fax: (+5581) $3223-5179$. E-mail: danielle_xande@yahoo.com.br 


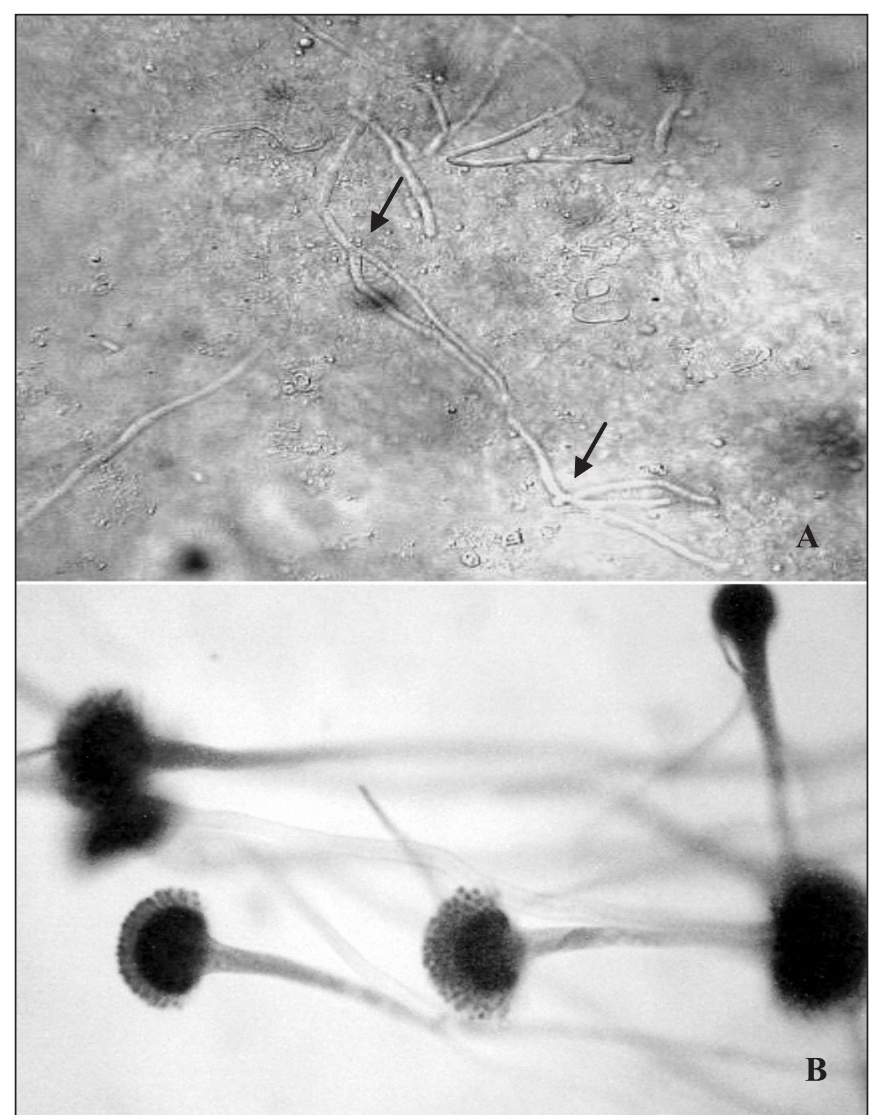

Figure 1. Direct examination with dichotomous branching and septation of hyphae (A). Typical conidiophores of Aspergillus fumigatus (B).

of the dialysis catheter was essential for eradicating the infection (10). According to the literature, antifungal therapy involving both intraperitoneal and systemic amphotericin $\mathrm{B}$, as well as itraconazole should be used $(12,26,28)$.

\section{Case 2}

A 45-year-old hypertensive male with a prior history of cardiac insufficiency was admitted with symptoms of acute onset of pain in both legs of two weeks duration and with pain in the right leg increasing gradually for the past one week. Investigations revealed normal scores of hemoglobin, $11.5 \mathrm{~g} \%$; urea, $25 \mathrm{mg} \mathrm{dl}^{-1}$; creatinine, $0.7 \mathrm{mg} \mathrm{dl}^{-1}$ and glucose, $95 \mathrm{mg} \mathrm{dl}^{-1}$. An aortogram undergone on the first day after admission revealed total occlusion of right common iliac artery and left common femoral arteries, following which he underwent a bilateral femoral embolectomy on the second post admission day.

The clot from the femoral artery was sent to the microbiology laboratory for culture, which grew A. fumigatus on solid media after $48 \mathrm{~h}$ of incubation $(14,23)$. On the first postoperative day
(POD) he was started on amphotericin B at $0.25 \mathrm{mg} \mathrm{kg}^{-1}$ day $^{-1}$ gradually increasing to $1 \mathrm{mg} \mathrm{kg}^{-1}$ body weight as an intravenous infusion. However, this had to be withheld from the second POD due to elevated renal parameters and nephrotoxicity.

A transesophageal echocardiography revealed fungal growth on the aortic valve which was mildly thickened. An embolectomy specimen and portions of the native aortic valve were also sent to the Medical Mycology Laboratory (Federal University of Pernambuco) for direct examination and culture. A $20 \% \mathrm{KOH}$ preparation revealed broad septate dichotomously branched hyphae. Small portions of the specimens were inoculated on routine media such as Sabouraud dextrose agar with $50 \mathrm{mg}$ chloranphenicol/L. Cultures were incubated at room temperature and at $37^{\circ} \mathrm{C}$. After $48 \mathrm{~h}$ of incubation the specimens cultured exhibited fungal growth typical of Aspergillus spp. Identification through macroscopic and microscopic characteristics was conducted according to Hoog et al. (14) and Rapper and Fennel (23).

The patient suddenly developed ventricular tachycardia and ventricular fibrillation and had a sudden cardiac arrest and was immediately intubated and put on ventilatory support. The patient rapidly went to fatal outcome, showing signs of fungal sepsis, including massive increase in leukocyte count, acute phase parameters and abnormal liver function tests.

\section{COMMENTS AND DISCUSSION}

\section{Case 1}

Despite improvement in the long-term survival of patients with systemic lupus erythematosus (SLE), infection remains a major cause of morbidity and mortality (32).

In the case 1 prompt systemic antifungal therapy and removal of the dialysis catheter were both essential for survival of this patient $(4,19)$. Several fungal species have been implicated as causal agents in dialysis-related peritonitis, including Candida, Aspergillus, Paecilomyces, Penicillium, Acremonium $(7,31)$ and patients with systemic lupus erythematosus are easily infected with fungi, bacteria, or other infectious organisms $(6,13,25)$. In this case, the dialysis catheter may have been contaminated and probably served as a portal of entry.

Many studies have examined the risk factors that predispose to infection in SLE patients with variable results. Major clinical predictors identified include active lupus, lupus nephritis and renal insufficiency. Use of corticosteroids at doses greater than $20 \mathrm{mg}$ to $60 \mathrm{mg}$ daily have been reported to increase the risk of infection $(9,21,22)$.

A myriad of intrinsic and acquired defects in both humoral and cellular immunity have been documented in patients with lupus. Breakdown of cutaneous and mucosal surfaces due to vasculitis may serve as a portal of entry for fungi. Leucopenia and lymphopenia are common in SLE patients with or without concomitant immunosuppressive therapies $(24,32)$. 
Systemic fungal infections, such as candidiasis and aspergillosis, which commonly occur in immunocompromised hosts, are fortunately uncommon in lupus patients $(11,27)$. Nonetheless, early diagnosis and prompt treatment are paramount to prevent a potentially fatal outcome.

\section{Case 2}

Until recently, heart mycotic infections were relatively uncommon but they may be increasing in frequency as a result of opportunistic infections in patients undergoing long-term administration of antibiotics, immunosuppressive therapy, organ transplantation, anticancer chemotherapy, or steroid hormone therapy in patients with acquired immunodeficiency syndrome (AIDS); or in patients fitted with prosthetic valves $(1,8,30)$. These new cases are often associated with disseminated fungal infection and are usually fatal (18).

Invasive aspergillosis is the most common mold infection occurring in immunocompromised patients and the second most common agent, after Candida species, to cause fungal endocarditis (18).

Aspergillus species may often contaminate hospital rooms and supplies and may inadvertently gain entrance into susceptible patients through many portals including surgical procedures (29). These fungi have been reported as a cause of both native and prosthetic valve endocarditis (3), which is occasionally a manifestation of disseminated aspergillosis.

The resultant fungal growth is often large and friable, and carries a high risk of embolic complications. Because of the poor penetration of amphotericin B into the growth, in addition to the risk of embolic complications, early surgical intervention with valve replacement is generally undertaken, especially in the setting of prosthetic valve endocarditis $(3,5)$. An occasional case has been successfully managed with amphotericin B and flucytosine alone $(5,26)$.

\section{CONCLUSIONS}

This report underscores the importance of A. fumigatus infection as severe condition and abruptly fatal associated with pre-existing factors such as systemic lupus erythematosus and cardiac post-operative complications presented herein as a usual pattern of immunosuppression.

\section{RESUMO}

\section{Aspergilose invasiva associada ao lúpus eritematoso sistêmico e a complicação cardíaca pós-operatória}

Aspergillus é um fungo ubíquito que pode causar uma variedade de síndromes clínicas. Este fungo tem emergido como agente de infecções sistêmicas e tem conquistado considerável importância para saúde pública. Este trabalho descreve dois casos de aspergilose invasiva causada por A. fumigatus em pacientes imunossuprimidos e relata a importância da identificação precoce em infecção por Aspergillus associada ao lúpus eritematoso sistêmico e a complicações cardíacas pósoperatórias.

Palavras-chave: Aspergillus fumigatus, micose oportunista, lúpus eritematoso sistêmico, complicações cardíacas pós-operatórias.

\section{REFERENCES}

1. Atkinson, J.B.; Conner, D.H.; Robinowitz, M.; McAllister, H.A.; Virmani, P. (1984). Cardiac fungal infections: review of autopsy findings in 60 patients. Hum. Pathol., 15, 935-942.

2. Balloy, V.; Huerre, M.; Latgé, J.P.; Chignard, M. (2005). Differences in patterns of infection and inflammation for corticosteroid treatment and chemotherapy in experimental invasive pulmonary aspergillosis. Infect. Immunol., 73(1), 494-503.

3. Barst, R.J.; Prince, A.S.; Neu, H. (1981). Aspergillus endocarditis in children: case report and review of the literature. Pediatrics, 68, 7378 .

4. Bibashi, E.; Memmos, D.; Kokolina, E.; Tsakiris, D.; So.anou, D.; Papadimitriou, M. (2003). Fungal peritonitis complicating peritoneal dialysis during an 11-year period: report of 46 cases. Clin. Infect. Dis., 36, 927-931.

5. Bogner, J.R.; Luftl, S.; Middeke, M. et al. (1990). Successful drug therapy in Aspergillus endocarditis. Dtsch. Med. Wochenschr, 115, 1833-1837.

6. Bouza, E.; Moya, J.G.; Munoz, P. (2001). Infections in systemic lupus erythematosus and rheumatoid arthritis. Infect. Dis. Clin. North Am., 15, 335-361.

7. Bren, A. (1998). Fungal peritonitis in patients on continuous ambulatory peritoneal dialysis. Europ. J. Clin. Microbiol. Infect. Dis., 17(12), 839-843.

8. Cox, J.N.; Di Dio, F.; Pizzolato, G.P; Lerch, R.; Pochon, N. (1990). Aspergillus endocarditis and myocarditis in a patient with the acquired immunodeficiency syndrome (AIDS). A review of the literature. Virchows Archiv. Pathol. Anat., 417, 255-259.

9. De Luis, A.; Pigrau, C.; Pahissa, A.; Fernandez, F.; Martinez-Vazquez, J.M. (1990). Infections in 96 cases of systemic lupus erythematosus. Med. Clin. (Barc), 94, 607-610.

10. Denning, D.W. (1998). Invasive aspergillosis. Clin. Infect. Dis., 26, 781-805.

11. Fantini, F.; Cimaz, R. (2003). A fatal case of systemic lupus erythematosus complicated by acute pancreatitis, invasive aspergillosis and features of thrombotic thrombocytopenic purpura. Lupus, 12, 418-421.

12. Georgiev, V.S. (1998). Aspergillus species in infectious disease in immunocompromised hosts. CRC Press, Boca Raton, FL.

13. Greenberg, S.R. (2000). Infections in the immunocompromised rheumatologic patient. Crit. Care Clin., 18, 931-956.

14. Hoog, G.S.; Guarro, J.; Gené, J.; Figueras, M.J. (2000). Atlas of clinical fungi. Centraalbureau voor Schimmelcultures, Utrecht.

15. Lin, C.M.; Tsai, Y.H.; Huang, C.C.; Lee, C.H.; Chiang, P.C.; Huang, S.F.; Liu, H.P. (2006). Invasive pulmonary aspergillosis and pulmonary cryptococcosis really coexist in immunocompromised host. J. Infect., 53, 55-58.

16. Lumbreras, C.; Gavaldà, J. (2003). Aspergilosis invasora: manifestations clínicas y tratamiento. Rev. Iberoam. Micol., 20, 79-89. 
17. Miles, A.M.; Barth, R.H. (1995). Aspergillus peritonitis: therapy, survival, and return to peritoneal dialysis. Am. J. Kidney Dis., 26, 80-83.

18. Muehrcke, D.D. (1995). Fungal prosthetic valve endocarditis. Semin. Thorac. Cardiovasc. Surg., 7, 20-24.

19. Nannini, E.C.; Paphitou, N.I.; Ostrosky-Zeichner, L. (2003). Peritonitis due to Aspergillus and zygomycetes in patients undergoing of vancomycin versus cefazolin as initial therapy for peritonitis peritoneal dialysis: report of 2 cases and review of the literature. Diagn. Microbiol. Infect. Dis., 46, 49-54.

20. Nguyen, M.H.; Muder, R.R. (1994). Aspergillus peritonitis in a continuous ambulatory peritoneal dialysis patient: case report and review of the literature. Diagn. Microbiol. Infect. Dis., 20, 99-103.

21. Noel, V.; Lortholary, O.; Casassus, P. et al. (2001). Risk factors and prognostic influence of infection in a single cohort of 87 adults with systemic lupus erythematosus. Ann. Rheum. Dis., 60, 1141-1144.

22. Paton, N.I.; Cheong, I.K.; Kong, N.C.; Segasothy, M. (1996). Risk factors for infection in Malaysian patients with systemic lupus erythematosus. Q. J. Med., 89, 531-538.

23. Rapper, K.B.; Fennel, D.I. (1977). The genus Aspergillus. Publishing Company Malabar, Florida.

24. Rivero, S.J.; Diaz-Jouanen, E.; Alarcon-Segovia, D. (1978). Lymphopenia in systemic lupus erythematosus. Clinical, diagnostic, and prognostic significance. Arthritis Rheum., 21, 295-305.

25. Schattner, A.; Kagan, A.; Zimhony, O. (2006). Aspergillus peritonitis in a lupus patient on chronic peritoneal dialysis. Rheumatol. Int., $26,762-764$.
26. Stevens, D.A.; Kan, V.L.; Judson, M.A.; Morrison, V.A.; Dummer, S.; Denning, W.; Bennett, J.E.; Walsh, T.J.; Patterson, T.F.; Pankey, G.A. (2000). Practice guidelines for diseases caused by Aspergillus. Clin. Infect. Dis., 30, 696-709.

27. Tanaka, H.; Suzuki, K.; Nakahata, T. et al. (2002). Disseminated candidiasis following prednisolone therapy in systemic lupus erythematosus. Pediatr. Int., 44, 702-704.

28. Tanis, B.C.; Verburgh, C.A.; Van't Wout, J.W., et al. (1995). Aspergillus peritonitis in peritoneal dialysis: case report and a review of the literature. Nephrol. Dial. Transplant., 10, 1240-1243.

29. Verghese, M.; Bernard, J.G.; Brent, A.W.; Warren, K.L.; James, W.; Tilbury, R.T.; Barry, R.D.; Holmes, D.R. (2004). Outcomes in patients with diabetes mellitus undergoing percutaneous coronary intervention in the current era: a report from the prevention of REStenosis with tranilast and its outcomes (PRESTO) trial. Circulation, 109, 476480 .

30. Walsh, T.J.; Hutchins, G.M. (1979). Aspergillus mural endocarditis. Am. J. Clin. Pathol., 71, 640-644.

31. Wang, A.Y.; Yu, A.W.; Li, P.K.; Lam, P.K.; Leung, C.B.; Lai, K.N.; Lui, S.F. (2000). Factors predicting outcome of fungal peritonitis in peritoneal dialysis: analysis of a 9-year experience of fungal peritonitis in a single center. Am. J. Kidney Dis., 36, 1183-1192.

32. Woon-Leung, N.G. (2006). Infections in patients with systemic lupus erythematosus. APLAR J. Rheumatol., 9, 89-97. 